\title{
IDEAS IN ECLLOGY AND EVILUTION - A new open-access model dedicated to the rapid release of creativity in peer-review publication
}

\author{
Lonnie W. Aarssen
}

L.W. Aarssen (aarssenl@queensu.ca), Dept. of Biology, Queen’s University, Kingston, ON, Canada, K7L 3N6

"It is better to be wrong than boring".

$$
\text { - Jacob Weiner }
$$

It may seem bold, if not brazen, for the first words published in a new peer-reviewed journal to suggest wrong is right. It may seem scurrilous to suggest the broken clock is still right twice a day. And it may seem to most that only a dreamer would ponder the value of a simple stone found along a beach.

Yet, commonly in the progress of science, it is necessary to be wrong before choosing the right path along the often circuitous journey that leads to truth. The broken clock owner needs to find a way to make the flawed timepiece right more often. Repair? Replace? That's discovery. The stone on the beach may indeed turn out to be worthless, but another one discovered nearby becomes a beautiful sculpture when the inspired beachcomber is an Inuit artisan. That's creativity. Wrong can be exciting, especially when it's instrumental in the process of discovery. Creativity, challenge, and controversy are the catalysts of scientific enquiry.

And so, acknowledging the complex and often nebulous interplay between wrong, right and boring, we launch IDEAS IN EcRlogy AND EVILUTION (http://library.queensu.ca/ojs/index.php/IEE). It's an open-access, peer-reviewed publication designed for forward-thinking ecologists and evolutionists. IDEAS IN Ecalagy AND EVםLution will publish only lively, short forum-style articles that develop new ideas or that involve original commentaries on topics broadly focused on applied or fundamental ecology or evolution. They may encompass any level of biological organization, and involve any taxa, including humans. Articles may concern subject matter within any recognized sub-discipline of ecology or evolution, or they may be broader in scope, including articles that aim to inform fields of study outside of biology. All articles will be joined by a conceptual foundation in the core principles of ecology and evolution studied by biologists.

Maybe this sounds traditional. But here's the difference: IDEAS IN EcRLgGY AND EVILUTION will get under your skin. As a rapidly published repository for cutting-edge, novel thinking and opinionpieces, it will make readers raise an eyebrow with intrigue. Modelers, empiricists, educators and the media will consider it a catalogue, brimming with original ideas and hypotheses that have been critically evaluated by professional biologists. The contents can be explored, debated, tested and tried on wide audiences. As a reliable source of inspiration, IDEAS IN Ecalogy AND Evalution will guide the direction and progress of future research and public awareness in ecology and evolution. And it will never be boring.

\section{Summary of unique combination of features}

- A novel scope, publishing exclusively short 'ideas and perspectives' - style papers, not reviews, and with no experimental data or mathematical modelling, thus serving as a rapid and easily accessible source of inspiration for further research and public debate aimed at a broad base of readership, from students to professionals in both science and the media.

- The speed of 'blog-style' communication combined with formal credit as a peer-reviewed publication; accepted papers are published on-line, with volume 
and page numbers, within five days of acceptance and receipt of signed publication agreement;

- No-blind reviewing; referees are automatically acknowledged within published papers;

- Credit for referees; referees are paid, both for their reviewing service and to forfeit their anonymity as a public endorsement (or counter-argument) for published papers;

- Optional credit for referees through no-cost peerreviewed publication of their response to reviewed papers;

- Additional post-publication review through 'commentaries' (also peer-reviewed) submitted by readers;

- Referee registry with 'email-alerts' to provide notification of the latest manuscripts available for review;

- Efficient checklist/questionnaire-based platform for referees to streamline manuscript evaluation;

- Completely transparent protocol for decisions to accept or reject, available to authors; rejection is never based on arbitrary journal 'page limits', or on editorial imperatives to boost journal impact factor.

\section{Riding on a revolution in science communication}

The 'open' concept ('open-access', 'open-science') is poised to transform communication in science. It is quickly expanding the ability "not just to consume online information but to publish it, edit it and collaborate about it - forcing such old-line institutions as journalism, marketing and even politicking to adopt whole new ways of thinking and operating ... Since the time of Galileo and Newton, scientists have built up their knowledge about the world by 'crowd-sourcing' the contributions of many researchers and then refining that knowledge through open debate” Waldrop (2008).

According to Waldrop (2008), the transformation to open-science will be driven by the "fear factor"; "if you wait for the journals, your work won't appear for another six to nine months. But with open science, your claim to priority is out there right away." The 'credit' problem however remains a big barrier; "the peerreviewed paper is the cornerstone of jobs and promotion, ... Scientists don't blog because they get no credit for that ... publications were always the one thing you could measure. Now, however, as more of this informal communication goes online, that will get easier to measure, too" (Waldrop 2008).

IDEAS IN ECRLGGY AND EVRLuTION solves the credit problem by combining all the advantages of rapid, open-concept communication with formal credit as a peer-reviewed publication of original ideas and commentaries.

\section{Rationale for a new journal}

The mere formulation of a problem is far more essential than its solution, which may be merely a matter of mathematical or experimental skill. To raise new questions, new possibilities, to regard old problems from a new angle requires creative imagination and marks real advances in science.

$$
\text { - Albert Einstein }
$$

The mission of science is to seek truth. We are guided in this mission not just by the generation of data but also by the generation of ideas. Both have been, and always will be essential to the progress of science (Aarssen 1997, Gardner et al. 2007). But data are subject to measurement error, scientific misconduct, and other sources of bias resulting from the imperfection of human skills and the subjectivity of human nature (e.g. Ioannidis 2005, Martinson et al. 2005, Montgomerie and Birkhead 2005, Lortie et al. 2007, Titus et al. 2008, Young et al. 2008). Our confidence in data, therefore, is rarely as complete as we would like, often leaving questionable inspiration and qualified recommendations. Ideas, in contrast, are not encumbered by these sources of error and bias, and their plausibility and merit can be judged objectively. Those ideas that survive assessment, therefore, provide bias-free inspiration and recommendations in the quest for truth. This in turn can promote empirical research that is driven by interesting and important questions, instead of just a 'fishing expedition', where data collection is used to find interesting and important questions (often unsuccessfully), motivated by a need to look busy (Weiner 1995).

Yet, despite the importance of idea development to the progress of science, new ideas are very often not assessed objectively and are difficult to get published. Good empirical studies that support established theory are especially easy to publish in traditional refereed journals. Even mediocre data seem to be easily publishable, judging from the fact that about half of the papers published in science never get cited (Hamilton 1991), and many papers even in high-impact factor journals get very few citations (Koricheva \& Leimu 2005). By comparison, authors who propose good novel ideas have a much harder time getting their manuscripts accepted for publication (e.g. see Campanario 1993, 1995, 1996).

It appears, therefore, to be part of human nature to be strongly skeptical of new ideas. Of course this is a good thing for science, where progress depends on new ideas being 'put to the test'. But it is not a good thing when constructive criticism turns to aggressive bias. Publication bias in particular, limits the opportunities for new ideas to be put to the text. When a new idea 
challenges, proposes an alternative view, or recommends a change of perspective for an established body of theory, it can be very difficult to find referees who do not have a conflict of interest. Many referees embrace established theory with tenacity, either because they contributed to its development, or because their own research is consistent with it, or may depend upon it for validation. If the new idea casts some doubt on the value or potential impact of the referee's own research, then the referee may perceive the idea as a threat. Other referees may feel threatened simply because they have 'new-idea-envy'. "Great spirits have always encountered violent opposition from mediocre minds " - Albert Einstein.

These effects generate a systemic resistance to new ideas, often associated with unfair and sometimes hostile derogatory accusations and labeling such as 'hand-waving', ‘just-so stories', and 'arm-chair ecology' leveled against authors who propose new ideas. These referee biases pre-dispose recommendations for rejection of new ideas by journal editors, with reasons that at first glance may appear credible and convincing, but upon closer examination, are often based on grounds that are subjective, debatable, and/or weakly argued. The journal editors, who are often over-worked and under-paid, are in turn readily inclined to follow the referees' recommendations in order to relieve the exasperation of having too many manuscripts that need clearing off their desks, which in most cases is a consequence of the arbitrarily limited number of 'pages' available in the journal for printing them all - another source of bias, unjustified in the age of electronic communication. The author must then submit the new idea to another journal, and perhaps another after that. Eventually, perhaps a year or more later, acceptance for publication may be found, but only provided that the author's available time, energy, or morale has not expired first.

The rejection of manuscripts resulting from the above process represents a crippling source of bias and delay in the progress of science, imposed to a large extent by dominant elitists who often hold the power in institutions of peer-review academic journalism. An obsession with impact factor has given many journals (and authors) a blurred vision of the purpose of science (Raff et al. 2008). Addressing these problems requires a new model of peer-review publication. IDEAS IN Ecalagy AND Evalution represents a completely transparent peer-review publication model that rejects elitism, guards against sources of publication bias, and serves to break down traditional barriers to the release of creativity. Its mission is to promote wider dissemination and more rapid flow, evaluation, and maturation of new ideas (and their rejection based on objective unbiased criteria), and hence, speed the progress of science. Importantly, because articles are published only on-line, there is no bias resulting from the arbitrary page-space limitations imposed routinely by paper-based traditional journals, as a self-serving mechanism to maximize journal impact factor.

\section{A novel scope}

There are lots of journals that publish reports of empirical studies, lots that publish mathematical modeling, and lots that publish review articles. A few ecology / evolution journals have small forum-type sections, where new ideas can be published. IDEAS IN Ecalogy AND Evalution, however, is the first journal in its field to be dedicated exclusively to forum / commentary type papers.

All papers submitted to IDEAs IN EcRLGGY AND Evalution are published provided that they meet the following five core criteria, as judged by the editors:

(i) The paper must present a genuinely novel idea or commentary.

(ii) The new idea /commentary must be well-argued and plausible.

(iii) The paper must demonstrate the potential for the new idea /commentary to impact significantly on the subject area or broader discipline.

(iv) The paper must clearly differentiate the idea or commentary from any previously published similar ideas or commentaries.

(v) A new idea must be accompanied by a proposal for testing the idea, even if it is completely impractical with current technology. Testability may be addressed directly, e.g. through empiricism, or in terms of the consilience of inductions. $^{1}$

(see also “Author Guidelines” at: http://library.queensu.ca/ojs/index.php/IEE/about/submi ssions\#authorGuidelines

\footnotetext{
${ }^{1}$ William Whewell (1840, “The Philosophy of the Inductive Sciences”) explained that, "The Consilience of Inductions takes place when an Induction obtained from one class of facts, coincides with an Induction obtained from another different class. Thus Consilience is a test of the truth of the Theory in which it occurs." Much of the history of support for Darwin's theory of evolution is based entirely on this form of testability.
} 


\section{A novel peer-review model}

Referees for IDEAS IN EcRLGGY AND EvםLutIon are not anonymous; they are paid - not just for their reviewing services, but importantly, they are paid to forfeit their anonymity. In other words, in the event that the paper is published, payment of referees secures their consent to reveal their identities directly within the published paper - as having refereed the paper. Referee identity is also revealed to authors of rejected papers. Referees must agree to these conditions in advance, before receiving the paper for review. This is done on-line, and the referee is paid upon receipt of the review (see "Peer Review Guidelines" at http://library.queensu.ca/ojs/index.php/IEE/about/editori alPolicies\#peerReviewProcess). We anticipate that referees will be particularly attracted to the efficient 'pipeline' model for submitting reviews (see Appendix). In this way, a well written paper that proposes a novel, plausible, and testable idea that has potential to impact on the discipline can be quickly reviewed, with a referee stipend (currently \$150) that is easily earned after a few mouse clicks on a standard form, and with no requirement for additional written comments.

In addition to this monetary incentive, referees also receive another incentive for giving up their anonymity and for providing a high quality review. If the paper is accepted for publication, each referee is entitled to publish his views on the paper as a companion article peer reviewed by both the editors and the author; the author of the original paper is, in this case, required to provide a 'review of the review' as a concluding section within the original paper (see Appendix). This provides the referees with a peer-reviewed publication within the journal without being charged the usual author fees (see below). In this sense therefore, referees play a role that is similar to that of paid syndicated columnists that provide reviews for new books and movies within the popular media. Some talented professionals might develop respected reputations as critics in high demand, and collect a lucrative source of income accordingly.

Another important feature of this journal is a referee registry. Potential referees may register on-line with the journal to receive regular 'email alerts', containing notification of recently submitted manuscripts that are in need of referees 'for hire'. The email alert includes information on how the referee can submit an application to review a particular paper. Hence, this journal is expected to generate a community of active, motivated, high quality referees that keep an eye on submissions. We anticipate that this will avoid the perennial and growing problem that many editors of traditional journals now face in trying to find referees that are willing to review.

Referee registration allows the building of a database of referees and their credentials, which serves to automate the review process, providing a streamlined mechanism for editors to quickly verify qualifications, and to approve and assign referees for a particular paper. Only referees that hold a $\mathrm{PhD}$, or are registered in, and expected soon to complete, a PhD program, are enlisted. Preference is given to referees that hold an academic appointment at an accredited post-secondary educational or research institution.

At the time of submission, authors must provide the names, affiliations and email addresses of at least three potential referees who would be qualified to review their manuscript. These may or may not be used at the discretion of the editors.

The above scheme provides important advantages over traditional models of peer-review. Most importantly, it provides a method of 'quality assurance' for reviews by putting in place strong incentives for referees to do a good, honest job - because the referee's name will be 'on the line' through his/her identification within the paper, should it be accepted. If the referee truly does support the paper, then his/her identification as a referee within the paper speaks for itself as an endorsement, and so 'all is well' - i.e., the referee may then have no particular interest in publishing a companion response paper. However, if the referee does not support the paper, or if she has her own views for modification or elaboration of the proposed idea, then she should be compelled to provide a wellreasoned argument in the event that the paper is nevertheless published (with her name necessarily identified); the referee's 'well-reasoned argument' can then be published as well (at her request), thus giving the referee the assurance of having her views published and clarified for readers. In order to be published, of course, the review must meet the same standard of quality as for all submitted manuscripts.

At the end of this review process, therefore, each of the three contributors (author plus two referees) may get individual credit for their own separate peer-reviewed publications of their proposals, critiques, revisions, and/or development of the idea, thus promoting rapid and thorough evaluation and maturation of the idea. With refereed publications of their own as incentives (together with monetary remuneration), we anticipate that referees will be inclined to be objective, thoughtful, and prompt in their review of the manuscript, thus promoting rapid high-quality reviews. Once the author's idea and its evaluation by referees are published, readers of the journal should be well equipped to make informed predictions concerning the value of the idea and its likelihood of affecting the future progress of the discipline. Moreover, readers also have the opportunity to provide further development/critique of the idea through submission of a Commentary article to the journal. This in turn provides additional (post-publication) peer-review of the 
original paper.

\section{A novel financial policy}

Authors pay a submission fee (currently \$400) at the time of submission. From these funds, two referees are paid (currently $\$ 150$ each). If the paper is accepted for publication, authors are charged an additional processing fee (currently \$300) to cover handling and publication costs. Having page and publication charges is not novel; what is novel for this journal however, is that some of the cost to authors - the submission fee - is upfront, and does not guarantee publication (although this fee is refundable in certain instances - see below).

At first this may sound off-putting. However, there are at least two reasons to consider this a reasonable and worthwhile fee for authors. First, the requirement that authors pay for reviewing service is no different from the payment for consultation fees that is routinely practiced in most other professional domains. Referees are busy people and their time is valuable. Authors commonly complain that they receive poor reviews from journals, and journals commonly find it difficult to even find people who are willing to review. The traditional view - that referees should feel obliged to provide their reviewing time as a gratuitous service to the profession - is a noble idea, but in practice encourages freeloaders. Authors want good, fast reviewing, but nothing that is both good and fast comes cheap; it requires incentive, which involves referee compensation that is fair and meaningful.

Second, when paying this submission fee, authors are free of worry (unlike with many traditional journals) that their paper might be at risk of being rejected based on biased arbitrary criteria like page limits, or editorial imperatives based on elitist 'impact factor' goals to publish 'only the best of the best'. Authors have completely transparent access to the protocol/rubric used by editors for decisions to accept or reject (see Appendix). No other journal provides this level of comfort to authors. If the author's idea really is novel, plausible, potentially testable, and is likely to impact on the discipline, the paper will be published. On the other hand, if it has serious flaws, then a $\$ 400$ fee is a bargain for fast service that provides their detection, allowing the author to quickly re-focus and possibly rework an improved manuscript for a future submission. Of course an author might minimize the chance of this happening by asking colleagues to review the paper before submitting it to the journal, but like editors, authors also have difficulty finding colleagues who are not too busy to provide feedback on their manuscripts.
This up-front cost also provides an important efficiency advantage for both authors and the journal: it serves as a real incentive for authors to take great care in addressing the above five core criteria before submission, thus providing a filter for maximizing the likelihood that the journal will receive only relatively high quality papers. The editors want authors who have taken the time and effort to be confident in the quality of their paper. If an author is not willing to take the financial risk of the submission fee, it probably means that the paper is not very good anyway, and this filter minimizes the number of these papers on the desks of our editors. Accordingly, a low rejection rate is anticipated, not because the journal will 'publish anything', but because the above policy promotes high quality submissions.

Importantly, this policy also serves to alleviate disadvantage for authors with low funding sources; they can earn their own funds to cover the cost of the fees for their paper by registering with the journal as a potential referee, and applying to referee papers that are of interest to them that are advertised through email alerts (see above). After reviewing four papers, a referee will have earned enough remuneration to pay for virtually all of the fees associated with one accepted paper. [Note also that because the journal is open-access, authors who can afford to pay the author fees are subsidizing access to the journal for readers - e.g. in less developed countries - who cannot afford the journal subscription fees of more traditional journals].

The journal also includes a component for promoting and rewarding good editorial service, which is lacking in most contemporary journals. As an incentive, for every 10 published papers handled, an editor may submit a paper to the journal with all fees waived. Some of the processing fees collected for the 10 papers previously handled by the editor (currently $\$ 30$ per paper) is used to pay reviewers for a paper submitted by the editor. Editors may also elect to serve as referees of submitted manuscripts, thus providing them with the usual remuneration (currently $\$ 150$ per review).

The onus is on the author to provide manuscripts that will attract potential referees. If the editor is unable to secure referees for a paper, therefore, the author is refunded most (currently \$300) of the submission fee. Authors also receive this refund if the manuscript is rejected prior to review, because of failure to follow the required manuscript specifications. In addition, if a reviewer takes longer than four weeks to submit a review, the author is issued a refund (currently $\$ 150$ per late review). If a reviewer fails to submit a review within six weeks, the author will be notified and given the option to wait longer for the review, to request a replacement reviewer, or to withdraw the manuscript and receive a refund - currently $\$ 150$ - for each unsuccessful review attempt. 


\section{Visibility, impact, and readership}

As with all journals now, particularly open-access journals, visibility of a paper no longer depends on journal reputation or impact factor. Neither does it depend on payment of subscription fees, or having to wait for every paper issue to arrive at a library. Because of on-line publication, indexing/searching services like Google Scholar, plus advertisement through list-serves like ECOLOG and EvolDir, in addition to the journal's own email-alert service, IDEAS IN ECOLOGY AND

EvaLutian will have visibility for the entire world after just a few mouse clicks on a computer.

The 'best of the best' ideas and commentaries published in this journal will - like cream - rise naturally to the top, and will receive the merit that they deserve through future citation. Those ideas that turn out to be less profound or destined to be forgotten, and those that are ahead of their time and destined to be rediscovered in the future, can reside in perpetuity with DOI numbers and journal volume and page numbers within IDEAS IN ECOLOGY AND EVILUTION, without wasting paper and without collecting dust in multiple paper copies on the shelves of libraries around the world.

The readers of this journal will be those who are interested in newly published ideas and commentaries that might guide the direction of future research. We anticipate that new graduate students and grant applicants will be drawn to this journal when searching for topics to develop into research proposals. Journal clubs and graduate courses within University departments can look to this journal as a source of inspiring articles to focus on for discussion groups. IDEAS IN ECGLGGY AND EVGLUTION will provide a shopping catalogue for modelers and empiricists; a directory for educators and students, and a promotional flier for the general media.

The Henry Ford model for success was to do one thing really well. By being the only journal that specializes exclusively in the publication of ideas and commentary papers in ecology and evolution, we anticipate that authors of such papers will be encouraged to submit their work to IDEAS IN Ecology AND EVםLutian, both because of the visibility provided by a specializing journal, and because of the unnecessarily high rejection rates of other traditional journals. Most current journals don't even want to publish your speculation, or they want to severely restrict it. Reviewers and editors commonly request that authors 'tone down' the speculation in their Discussion, and some journals that feature 'perspectives' sections are willing to consider submissions only by invitation. In IDEAS IN EcoLogy AND EVםLution, we want speculation, and only speculation, and we are not so elitist to assume that only certain people have legitimate speculation, nor do we presume to already know who they are, waiting to be invited.

A recent review of how the internet has shaped science (Evans 2008) suggests that, because of the way that the growing volume of publications are now so readily available and presented to researchers through on-line searches, new ideas that don't receive attention early on may now be at greater risk of being overlooked or forgotten. IDEAS IN ECOLOGY AND Evalution provides a new publication model that will guard against this trend by showcasing new ideas, and by providing a conspicuous repository for retrieving and resurrecting important ideas and opinions that might be more easily lost in other journals.

So, next time that you have an interesting new idea, or a potentially important opinion, don't just sit on it. Take time to develop your idea or opinion carefully into a good manuscript, and submit it for peer-review to IDEAS IN ECOLOGY AND EVILUTION, where it can be quickly subjected to critical analysis, revision, debate, and further development - where it can therefore play a significant role in the maturation of theory within your broader discipline. Through the promotion of your original views in this journal, you can rapidly explore their full potential for the release of creativity within your academic or applied community, and within the public at large - creativity that is essential for driving the progress of research, and shaping the public valuation of science.

\section{Acknowledgements}

In developing the issues considered in this editorial, I have benefited greatly from feedback and discussions with several colleagues, including Tom Tregenza, Brandon Schamp, Jennifer Waugh, Owen Roberts, and especially Christopher Lortie.

\section{References}

Aarssen, L.W. 1997. On the progress of ecology. Oikos 80: 177-178. CrossRef

Campanario, J.M. 1993. Consolation for the scientist: sometimes it is hard to publish papers that are later highly cited. Social Studies of Science 23: 342362. CrossRef

Campanario, J.M. 1995. Commentary on influential books and journal articles initially rejected because of negative referees' evaluations. Science Communication 16: 304-325. CrossRef

Campanario, J.M. 1996. Have referees rejected some of the most-cited papers of all times? Journal of the American Society for Information Science 47: 302- 
310. $\underline{\text { CrossRef }}$

Evans, J. 2008. Electronic Publication and the Narrowing of Science and Scholarship. Science 321: 395 - 399. CrossRef

Gardner, J., Marsack, P., Trueman, J., Calcott, B. and R. Heinsohn. 2007. Story-telling: an essential part of science. Trends in Ecology and Evolution 22: 510. CrossRef

Hamilton, D.P. 1991. Research papers: who's uncited now? Science 251: 25. CrossRef

Ioannidis, J.P.A. 2005. Why most published research findings are false. PLoS Med 2(8): e124. CrossRef

Koricheva, J. and R. Leimu. 2005. What determines the citation frequency of ecological papers? Trends in Ecology and Evolution 20: 28-32. CrossRef

Martinson, B.C., Anderson, M.S. and R. de Vries. 2005. Scientists behaving badly. Nature 435: 737-738. CrossRef

Lortie, C.J., Aarssen, L.W., Budden, A.E., Koricheva, J.K., Leimu, R., and T. Tregenza. 2007. Publication bias and merit in ecology. Oikos 116: 1247-1253. CrossRef

Montgomerie, R. and T. Birkhead. 2005. A beginner's guide to scientific misconduct. ISBE Newsletter 17: 16-24.

Raff, M., A. Johnson, and P. Walter. 2008. Painful publishing. Science 321: 36. CrossRef

Titus, S.L., Wells, J.A. and L.J. Rhoades. 2008. Repairing research integrity. Nature 453: 980-982. CrossRef

Waldrop, M.M. 2008. Science 2.0 - Is open access science the future? Scientific American. http://www.sciam.com/article.cfm?id=science-2point 0

Weiner, J. 1995. On the practice of ecology. Journal of Ecology 83: 153-158. CrossRef

Young N.S., Ioannidis, J.P.A., and O. Al-Ubaydli. 2008. Why current publication practices may distort science. PLoS Med 5(10):e201 $\underline{\text { CrossRef }}$ 


\section{Appendix: The IEE review pipeline for manuscript evaluation}

(1) A paper is accepted as is, without revisions, if both referees check the choices associated with the red line trajectory in the 'pipeline' of Figure 1.

(2) If a referee selects A, B, or C in the 'pipeline' (Fig. 1) (based on core criteria $1-3$; see main text), then a subject editor from the Advisory Editorial Board is normally consulted to evaluate the referee's criticism. The paper is rejected if at least one referee provides well-reasoned support, as judged by the editors, for selecting points A, B, or C in the 'pipeline', and the referees' comments (with their identities revealed) are forwarded to the author. In this case, authors are not permitted to submit a revised paper under the same submission number (although they may pursue an entirely new submission with a cover letter that explains how they have addressed referee concerns from their earlier submission).

(3) If a referee selects A, B, or C in the 'pipeline', but in the judgment of the editors has NOT provided a wellreasoned supporting argument, then the referee's input in this case does not affect the editor's decision to accept or reject. If, after this, the editors have no sound argument for selecting points $\mathrm{A}, \mathrm{B}$ or $\mathrm{C}$, then the author is given the benefit of the doubt, and the paper is processed as indicated in (4). Importantly, if the referee's criticisms involving $A, B$ or $C$ are judged as debatable, the manuscript is likely to be accepted for publication and the editor will encourage the referee to publish his/her objections/concerns as a companion article (see below).

(4) After (3), or if neither referee selects A, B, or C in the 'pipeline', then the paper is accepted for publication provided that core criteria 4 and 5 (see main text), concerning points D, E, F, and G in the 'pipeline' (Fig. 1) can be met - as judged by the editor - either through published reviews from referees, or in a revised manuscript from the author. A member of the Advisory Editorial Board is normally consulted to facilitate this decision. If the paper is accepted, the referees must indicate at this point whether they wish to have their comments published as companion articles together with the accepted manuscript. The referee's review/response, if it is to be published, may be critical or supportive of the idea, but must - as judged by the editors - be based on substantive comments involving refutation (if debate regarding $A, B$ or $C$ is involved), further clarification, extension, modification, or revision of the author's original idea or commentary, and in particular must effectively address the reasoning provided in association with the selection of points $D, E$, $F$, or $G$ in the 'pipeline' of Figure 1, if applicable. Referee commentary based on identification of routine errors (e.g. in grammar) or minor oversights (e.g. failure to provide citation to a reference mentioned in the text) will not be published.

(5) At this stage, the decision to publish rests with the author, who may elect to withdraw the paper if he would prefer not to publish his original paper together with the published reviews from the referee(s).

(6) If both the author and at least one referee indicate their wish to publish in (4) and (5), then the author may elect to invite the referee(s) to co-author the paper, and this will be particularly encouraged by the editor if the referee has provided important further development or clarification of the author's original argument. Alternatively, the author (or the referee) may elect not to collaborate, but in this case the author must provide a review of the referee's responding article (limited to 1500 words and one illustration); this author's review (which may be supportive or may take the form of a rebuttal) must be incorporated as a concluding section under separate subtitle ('Response to referees') added to the end of the originally submitted manuscript. In this case, no revisions of content, to address the referee's responding comments, are permitted in the author's originally submitted text of the manuscript (except for referee corrections arising from routine errors or minor oversights - as judged by the editors). This arrangement is designed to maximize quality control because authors should be inclined under this arrangement to take great care in developing their original manuscript before it is submitted. In addition, with this arrangement, referees should be particularly inclined to provide high quality reviews because their reviews are in turn subjected to published peer-review by the submitting author, as well as peer review by the editors.

(7) In the event that one or both referees choose not to publish their reviews, the author of an accepted manuscript may revise the original manuscript in any ways that may be necessary to adequately address any comments from this/these referee(s). Some revisions, as determined by the editor, may be mandatory before final acceptance. Papers are published on-line within five working days of final acceptance, payment of the processing fee and receipt of the signed publication agreement. 


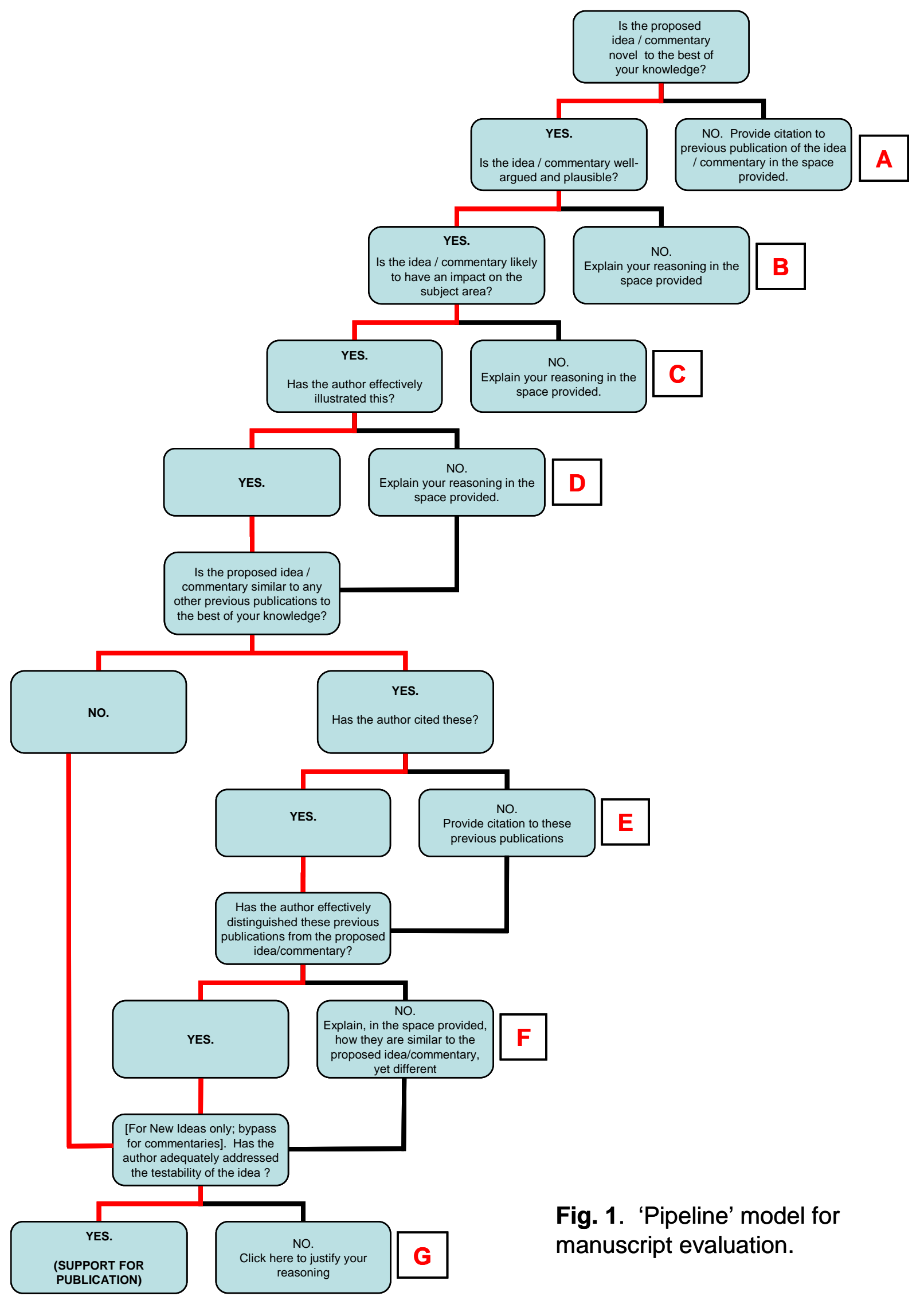

